\title{
OPEN A bacteriocin-based treatment option for Staphylococcus haemolyticus biofilms
}

\author{
Christian Kranjec ${ }^{1,5}$, Sofie S. Kristensen ${ }^{1,5}$, Karolina T. Bartkiewicz ${ }^{1}$, Mikkel Brønner ${ }^{1}$, \\ Jorunn P. Cavanagh ${ }^{2,3}$, Aparna Srikantam ${ }^{4}$, Geir Mathiesen ${ }^{1}$ \& Dzung B. Diep ${ }^{1 \bowtie}$
}

Bacteriocins are ribosomally-synthesized antimicrobial peptides, showing great potential as novel treatment options for multidrug-resistant pathogens. In this study, we designed a novel hybrid bacteriocin, Hybrid $1(\mathrm{H} 1)$, by combing the $\mathrm{N}$-terminal part and the $\mathrm{C}$-terminal part of the related bacteriocins enterocin K1 (K1) and enterocin EJ97 (EJ97), respectively. Like the parental bacteriocins, $\mathrm{H} 1$ used the membrane-bound protease RseP as receptor, however, it differed from the others in the inhibition spectrum. Most notably, $\mathrm{H} 1$ showed a superior antimicrobial effect towards Staphylococcus haemolyticus-an important nosocomial pathogen. To avoid strain-dependency, we further evaluated $\mathrm{H} 1$ against 27 clinical and commensal S. haemolyticus strains, with $\mathrm{H} 1$ indeed showing high activity towards all strains. To curtail the rise of resistant mutants and further explore the potential of $\mathrm{H} 1$ as a therapeutic agent, we designed a bacteriocin-based formulation where $\mathrm{H} 1$ was used in combination with the broad-spectrum bacteriocins micrococcin P1 and garvicin KS. Unlike the individual bacteriocins, the three-component combination was highly effective against planktonic cells and completely eradicated biofilm-associated S. haemolyticus cells in vitro. Most importantly, the formulation efficiently prevented development of resistant mutants as well. These findings indicate the potential of a bacteriocins-based formulation as a treatment option for S. haemolyticus.

Staphylococci are a diverse genus of Gram-positive bacteria, commonly found in the microbiota of skin and mucosal membranes of humans. Generally, staphylococci are divided into two groups: coagulase-negative (CoNS) and coagulase-positive staphylococci (CoPS), depending on the production of the clotting enzyme coagulase. For decades, the CoPS Staphylococcus aureus has been recognized as an important human pathogen, while CoNS have been considered commensal and regarded as mere contaminants when found in samples from infections ${ }^{1,2}$. Today, CoNS are recognized as major opportunistic nosocomial pathogens, particularly causing infections in immunocompromised patients and patients with indwelling medical devices ${ }^{3,4}$. Among CoNS, S. haemolyticus is receiving increased attention as a nonconical pathogen, being the second most frequently isolated CoNS in clinical settings ${ }^{1,5}$.

Compared to the more virulent $S$. aureus, few virulence characteristics have been determined as crucial for $S$. haemolyticus infections. One of these is its multidrug-resistant (MDR) phenotype ${ }^{6-8}$. Clinical isolates of $S$. haemolyticus are ranked as the most antibiotic-resistant CoNS, and they have frequently been reported as resistant to last-line antibiotics such as glycopeptides, making treatment options limited ${ }^{1,9,10}$. A variety of mechanisms contribute to the acquisition of antibiotic resistance. Notably, the S. haemolyticus genomes contain multiple insertions and single nucleotide polymorphisms (SNPs), allowing frequent genetic rearrangements ${ }^{3,8}$. The extreme genome plasticity likely allows $S$. haemolyticus to acquire antibiotic-resistant genes from its environment, often resulting in MDR hospital-adapted clones ${ }^{8}$. Equally significant is the horizontal gene transfer of antibioticresistance genes from $S$. haemolyticus to $S$. aureus strains observed in hospital outbreaks of methicillin-resistant S. aureus (MRSA), indicating that $S$. haemolyticus may act as a reservoir for resistance genes in hospitals ${ }^{11-13}$.

The ability to form biofilms and adhere to medical devices is another crutial virulence factor in S. haemolyticus infections $\mathrm{s}^{14}$. Biofilm formation allows microbial adhesion to biotic and abiotic surfaces, as well as shielding the bacteria from the host immune response and antibiotics ${ }^{15}$. Biofilm formation on indwelling medical devices is a major concern, as the increased antibiotic resistance makes infections more difficult to treat, often leaving

${ }^{1}$ Faculty of Chemistry, Biotechnology and Food Science, Norwegian University of Life Sciences, Ås, Norway. ${ }^{2}$ Pediatric Infections Group, Department of Pediatrics, University Hospital of North Norway, Tromsö, Norway. ${ }^{3}$ Pediatric Infections Group, Department of Clinical Medicine, UiT the Arctic University of Norway, Tromsö, Norway. ${ }^{4}$ Blue Peter Public Health and Research Centre, LEPRA Society, Hyderabad, India. ${ }^{5}$ These authors contributed equally: Christian Kranjec and Sofie S. Kristensen. ${ }^{凶}$ email: dzung.diep@nmbu.no 


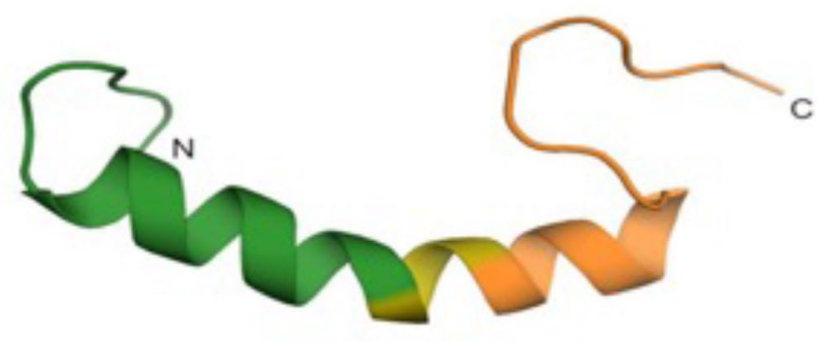

\section{K1}

MKFKFNPTGTIVKKLTQYEIAWFKNKHGYYPWEIPR

\section{EJ97 MLAKIKAMIKKFPNPYTLAAKLTTYEINWYKQQYGRYPWERPVA $\mathrm{H} 1$

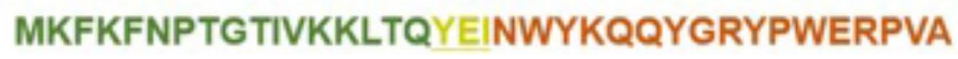

Figure 1. Predicted Structure and amino acid sequence of the hybrid bacteriocin and its parental bacteriocins. The predicted structure of the hybrid bacteriocin 1 (H1), formed by the N-terminal part of K1 (green) and the C-terminal part of EJ97 (orange). The central tripeptide sequence (YEI-underlined) in K1 and EJ97 serves as the joining segment in the fusion protein. The structure of $\mathrm{H} 1$ was modeled based on the NMR structural data of $\mathrm{K} 1^{23}$ using the structure prediction tool Swiss mode ${ }^{35}$.

surgical removal of the device as the only option ${ }^{14,15}$. There is limited knowledge about the molecular mechanisms underlying the formation of S. haemolyticus biofilm. However, their primary importance in infections is evident. Compared to the polysaccharide biofilms formed by S. epidermidis, S. haemolyticus forms biofilms mainly composed of proteins and DNA 6 . The ability to form biofilms combined with their high degree of MDR makes infections caused by $S$. haemolyticus increasingly challenging to combat. Due to their ability to form biofilms, persist and thrive in the hospital environment ${ }^{16}$, S. haemolyticus strains are emerging as a severe nosocomial threat.

To better control the increasing number of MDR pathogens, novel treatment options are needed. In this context, bacteriocins are receiving increased scientific and medical interest. Bacteriocins are small ribosomally synthesized antimicrobial peptides which are produced by bacteria to compete with other bacterial species for nutrients and ecological niches. Bacteriocins are generally believed to be produced by most bacteria, with the Staphylococcus genus being no exception. Several bacteriocins produced by staphylococci show prominent antistaphylococcal and bacteriolytic activities ${ }^{17}$.

Compared with traditional antibiotics, bacteriocins have several advantages, including low toxicity (particularly those expressed by lactc acid bacteria (LAB)), the ability to be bioengineered and high efficacy ${ }^{18}$. The high potency of bacteriocins has been demonstrated both in vitro and in vivo. Notably, bacteriocins exhibit high activity towards several clinically important species, including Streptococcus pneumonia ${ }^{19}$, MRSA ${ }^{17,20}$, Clostridium difficile $e^{21,22}$ and vancomycin resistant enterococci (VRE) ${ }^{23,24}$, thereby underlining the potential of bacteriocins as antimicrobial therapeutics. More importantly, bacteriocins have different modes of action than traditional antibiotics, making them active against MDR pathogens ${ }^{18}$.

Leaderless bacteriocins are synthesized without an N-terminal leader sequence and contain no post-translational modifications. This, along with their relatively small size (30-50 amino acids), makes them ideal for synthetic production. Enterocins K1 and EJ97 are two leaderless bacteriocins with potent and specific activity towards enterococcal species through an interaction with the membrane-bound site-2-protease RseP (Regulator of Sigma-E Protease $)^{23}$. RseP is a virulence factor ${ }^{25,26}$ involved in the stress response and processing of signaling peptides in several bacteria ${ }^{27-30}$, thus serving as a potential antimicrobial target. It is proposed that EJ97 and $\mathrm{K} 1$ interact specifically with RseP to create pores in the cell membrane, thereby leading to disrupted membrane integrity and cell death ${ }^{23}$. In the present study, we designed a novel hybrid bacteriocin designated Hybrid 1 (H1), which is composed of the N-terminal half of Enterocin K1 and the C-terminal half of Enterocin EJ97 ${ }^{23,31}$. Here we show that RseP serves as the receptor for $\mathrm{H} 1$ and that the hybrid bacteriocin has superior antimicrobial properties towards clinical S. haemolyticus isolates when compared with the parental bacteriocins. Moreover, we demonstrate that $\mathrm{H} 1$ acts synergistically with the broad-spectrum bacteriocins garvicin KS and micrococcin P1, not only to kill planktonic and biofilm-associated S. haemolyticus cells but also to prevent resistance development.

\section{Results}

The inhibition spectrum of the novel hybrid bacteriocin $\mathrm{H} 1$. Previous studies have indicated that the generation of hybrid bacteriocins can be an effective way to create novel antimicrobials with new and/or improved properties ${ }^{32-34}$. Inspired by these works we created a hybrid bacteriocin, called $\mathrm{H} 1$, formed by two sequence related enterocins: K1 and EJ97, the former being most active against E. faecium while the latter being most active against E. faecalis. $\mathrm{H} 1$ contains the N-terminal half of $\mathrm{K} 1$ and the C-terminal half of EJ97, sequence and predicted structure ${ }^{23,35}$, guided by the NMR data of K1, is shown in Fig. 1. When testing the antimicrobial activity against a panel of 50 bacteria from different genera and species (Table S1), the hybrid bacteriocin displayed good activity against selected species within the genera Staphylococcus and Streptococcus. Within the 


\begin{tabular}{|c|c|c|c|}
\hline \multirow[b]{2}{*}{ S. haemolyticus strains } & \multicolumn{3}{|c|}{ Bacteriocins $\left({ }^{*}\right)$} \\
\hline & K1 & EJ97 & H1 \\
\hline $4068^{\star *}$ & - & $++^{*}$ & $+++^{*}$ \\
\hline $4069^{* *}$ & - & $++^{*}$ & $+++^{*}$ \\
\hline $4070^{* *}$ & - & $++^{*}$ & $+++^{*}$ \\
\hline $4071^{* *}$ & - & $++^{*}$ & $+++^{*}$ \\
\hline $4072^{\star *}$ & - & $++^{*}$ & $+++^{*}$ \\
\hline $4073^{\star *}$ & - & $++^{*}$ & $+++^{*}$ \\
\hline 7067_4_56 & - & $++^{*}$ & $+++^{*}$ \\
\hline 7068_7_63 & - & $++^{*}$ & $+++^{*}$ \\
\hline 7067_4_66 & - & $++^{*}$ & $+++^{*}$ \\
\hline 7067_4_49 & - & $++^{*}$ & $+++^{*}$ \\
\hline 7067_4_84 & - & $++^{*}$ & $+++^{*}$ \\
\hline 7067_4_67 & - & $++^{*}$ & $+++^{*}$ \\
\hline 7067_4_71 & - & $+++^{*}$ & $+++^{*}$ \\
\hline 7067_4_28 & - & $+++^{*}$ & $+++^{*}$ \\
\hline 7067_4_48 & - & + & $+++^{*}$ \\
\hline 7067_4_21 & - & $++^{*}$ & $+++^{*}$ \\
\hline $7067 \_4$ _60 & ++ & $+++^{*}$ & $+++^{*}$ \\
\hline SH46 & - & $++^{*}$ & $+++^{*}$ \\
\hline SH01 & - & $+++^{*}$ & $+++^{*}$ \\
\hline SH09 & - & + & $+++^{*}$ \\
\hline SH04 & - & $+++^{*}$ & $+++^{*}$ \\
\hline SH10 & + & $+++^{*}$ & $+++^{*}$ \\
\hline SH47 & + & $+++^{\star}$ & $+++^{*}$ \\
\hline $\mathrm{SH} 14^{* *}$ & - & $++^{*}$ & $+++^{*}$ \\
\hline $\mathrm{SH} 20^{* *}$ & + & $++^{*}$ & $+++^{*}$ \\
\hline 7067_4_39** & - & + & $+++^{*}$ \\
\hline
\end{tabular}

Table 1. Inhibition spectrum of K1, EJ97 and $\mathrm{H} 1$ as assessed by the spot-on-lawn assay against 27 Staphylococcus haemolyticus strains. ${ }^{\star}$ Mutants observed after $24 \mathrm{~h} .5 \mu \mathrm{l}$ of each bacteriocin at $1 \mathrm{mg} / \mathrm{ml}$ was used in the spot-on-lown assay. Average Inhibition score $(n=3)$ indicates: “-”= No inhibition; "+" = Unclear zone; $"++"=$ zone $<1 \mathrm{~cm}$, and “ $+++"=$ zone $\geq 1 \mathrm{~cm}$. ${ }^{*}$ Strains where $\mathrm{H} 1$ resistant mutants where isolated from $1 \mathrm{mg} /$ ml spot-on-lawn inhibition zone.

former genus, it is interesting to note that $\mathrm{H} 1$ displayed increased activity against S. epidermidis and S. haemolyticus, compared with the parental bacteriocins. In addition, all three bacteriocins showed weak or no effect on S. aureus, S. arlettae and S. simulans; whereas EJ97 and H1 displayed a comparable antimicrobial effect against S. hominis. Similarly, among streptococci, H1 showed increased activity against $S$. thermophilus and S. uberis, but no activity against $S$. dysgalactiae. None of the bacteriocins had activity against Gram-negative bacteria (Table S1). Because of the superior effect of $\mathrm{H} 1$ against the important human pathogen S. haemolyticus, we focused further on the activity of $\mathrm{H} 1$ on this species.

To examine whether the activity of $\mathrm{H} 1$ was strain-depedent, a collection of 27 clinical and commensal $S$. haemolyticus strains derived from blood, urine and wound-associated infections were tested (Table S2). Using the spot-on-lawn assay, $\mathrm{H} 1$ was found to have better activity (i.e., larger inhibition zones) for $74 \%$ of the tested S. haemolyticus strains compared to K1 or EJ97 (Table 1). However, development of resistant colonies was observed within the inhibition zones for all 27 strains after a $24 \mathrm{~h}$ incubation (Table 1). Using the microtiter plate assay to follow the antimicrobial dynamics, $\mathrm{H} 1$ had minimum inhibition concentrations $\left(\mathrm{MIC}_{50}\right)$ in the range $0.1-0.78 \mathrm{mg} / \mathrm{ml}$ against the different $S$. haemolyticus strains after $5 \mathrm{~h}$ of incubation (Table S2) but resistance to $\mathrm{H} 1$ was progressively observed after 24 and $48 \mathrm{~h}$ incubation (data not shown).

RseP is required for $\mathrm{H} 1$ antimicrobial activity. Previous studies have shown that the enterocins K1 and EJ97 require the membrane-bound protease RseP to recognize and kill enterococcal cells ${ }^{23}$. It is logical to assume that H1, a hybrid of K1 and EJ97, targets the same receptor. To test this, we heterologously expressed the S. haemolyticus RseP in Lactobacillus plantarum WCFS1 ${ }^{36}$, which is resistant to the enterocin H1. As expected, L. plantarum expressing the $S$. haemolyticus rseP, showed sensitivity comparable to the parental S. haemolyticus strain, while L. plantarum harbouring the empty vector (pEV) was resistant to H1 (Fig. S1; Table 2).

The rseP gene is not the hot spot for mutations in the H1-resistant mutants. Although the role of RseP in the sensitivity of $S$. haemolyticus towards $\mathrm{H} 1$ was evident, we sought to confirm whether mutations were within $r s e P$ among the H1-resistant mutants. The rseP gene was therefore sequenced in a pool of 


\begin{tabular}{|l|l|l|}
\hline Strain & Relevant characteristics & $\mathbf{H 1}(\boldsymbol{\mu g} / \mathbf{m l})$ \\
\hline L. plantarum WCFS1 & WT of host strain & $>50$ \\
\hline L. plantarum WCFS1/pEV & Expressig empty vector & $>50$ \\
\hline L. plantarum WCFS1/pSIP401_SHRseP & Expressing RseP from S. haemolyticus 7067_4_21 & 0.39 \\
\hline
\end{tabular}

Table 2. Minimal inhibitory concentration (MIC) values $(\mu \mathrm{g} / \mathrm{ml})$ of $\mathrm{H} 1$ towards different $L$. plantarum strains.

\begin{tabular}{|l|l|l|}
\hline \multirow{2}{*}{ H1 resistant S. haemolyticus isolate } & Mutations $^{*}$ & \multicolumn{2}{|l|}{$\boldsymbol{r s e P}$} & escAB \\
\hline $7076 \_4 \_21 \mathrm{M} 1$ & - & $\begin{array}{l}\text { escB: c.855delT } \\
\text { p.Phe285fs }\end{array}$ \\
\hline $7076 \_4 \_21 \mathrm{M} 2$ & - & $\begin{array}{l}\text { escB: c.855delT } \\
\text { p.Phe285fs }\end{array}$ \\
\hline 4069 M3 & - & $\begin{array}{l}\text { ecsA: c.113G }>\text { A } \\
\text { p.Gly38Asp }\end{array}$ \\
\hline 4071 M3 & $\begin{array}{l}\text { c.1136_1139dupGTGG } \\
\text { p.R381fs }\end{array}$ & - \\
\hline 4072 M3 & - & $\begin{array}{l}\text { ecsB: c.51_52insT } \\
\text { p.Lys18fs }\end{array}$ \\
\hline
\end{tabular}

Table 3. Whole genome sequencing of selected $\mathrm{H} 1$ resistant mutants. ${ }^{*}$ Intact gene, c: Coding DNA, p: Protein, del: deletion, fs: frameshift, $>$ : Substitution, ins: Insertion, dup: duplication.

14 randomly selected H1-resistant mutants of S. haemolyticus. Surprisingly, only two mutants (4070 10_2 and 4071 1_4) had mutations within $r s e P$, both with amino acid substitutions. In contrast, no mutation within $r s e P$ was found for the remaining H1-resistant mutants. To solve this puzzle, we performed whole-genome sequencing (WGS) on five additional H1-resistant mutants and the respective wildtype (WT) counterparts (Table 3). Surprisingly, four sequenced mutants contained mutations within the genes ecs $A B$, encoding subunits of the ATP-binding cassette $(\mathrm{ABC})$ transporter $\mathrm{Ecs}^{37,38}$. The Ecs ABC transporter is known to be tightly connected with RseP in a secretory pathway in aerobic and facultative anaerobic Firmicutes, including staphylococci ${ }^{39,40}$. The last mutant contained a frame-shift mutation within $r s e P$ resulting in a truncated product (Table 3 ).

Micrococcin P1 and garvicin KS potentiate the activity of $\mathrm{H} 1$. The frequent resistance to $\mathrm{H} 1$ observed above, prompted us to investigate its synergistic effects in combination with other bacteriocins. To this end, the bacteriocins micrococcin P1 (MP1) and garvicin KS (GarKS) were chosen as they have been used in synergy studies before ${ }^{20,41}$. MP1 is a thiopeptide inhibiting protein synthesis ${ }^{42-45}$, while GarKS is a threepeptide bacteriocin with a yet unknown mode of action ${ }^{46}$. We initially evaluated the antimicrobial activity of the two bacteriocins against the six $S$. haemolyticus strains isolated from leprosy-associated plantar skin ulcers (4068-4073). For comparison, we also included the parental bacteriocins EJ97 and K1. We used the spot-onlawn assay where these strains were challenged with three different concentrations of each antimicrobial $(0.04$, 0.2 and $1.0 \mathrm{mg} / \mathrm{ml}$ ). As shown in Fig. 2, MP1 gave clear inhibition zones at all three concentrations while H1 gave inhibition only at the two highest concentrations. For GarKS and EJ97, some inhibition was seen only at the highest concentration. K1 did not result in any inhibition.

To investigate whether there was synergy between the three bacteriocins (H1, GarKS and MP1), a checkboard antimicrobial assay was performed. The selected strains were treated for 5,24 and $48 \mathrm{~h}$ with a range of concentrations of $\mathrm{H} 1$, GarKS and MP1 alone or in different combinations. The results are summarized in Fig. 3 and further details on individual $\mathrm{MIC}_{50}$ values for the tested strains can be found in Table S3. After a $5 \mathrm{~h}$ incubation, MP1 showed the strongest antimicrobial activity, with $\mathrm{MIC}_{50}$ values ranging between 0.02 and $0.15 \mu \mathrm{g} / \mathrm{ml}$, whereas $\mathrm{H} 1 \mathrm{had} \mathrm{a} \mathrm{MIC}_{50}$ of $0.78 \mu \mathrm{g} / \mathrm{ml}$ against all strains. Consistent with the antimicrobial test in Fig. 2, GarKS was the least active bacteriocin, with $\mathrm{MIC}_{50}$ values ranging between 3 and $24 \mu \mathrm{g} / \mathrm{ml}$ (Fig. 3; Table S3).

The prolonged exposure for 24 and $48 \mathrm{~h}$ resulted in a progressive increase in the $\mathrm{MIC}_{50}$ values for all treatments, a sign of resistance development. In agreement with the results above, H1 alone readily led to the generation of resistance among all tested strains (Fig. 3; Table S3). On the other hand, while the double combinatorial treatments (GarKS/MP1; H1/GarKS; H1/MP1) did not significantly increase the antimicrobial activity of the bacteriocins, combining all three bacteriocins (called the tricomponent combination) efficiently inhibited the microbial growth at all time-points. Interestingly, treatment with the tricomponent combination led to contained $\mathrm{MIC}_{50}$ values, with reduced inter-strain variability and displayed no sign of resistance development (Fig. 3). This was particularly evident at the 24 and $48 \mathrm{~h}$ time-points compared to the other treatments (Table S3).

Taken together these data indicate that the tricomponent combination had not only a superior antimicrobial activity but was also able to prevent resistance development. 
K1
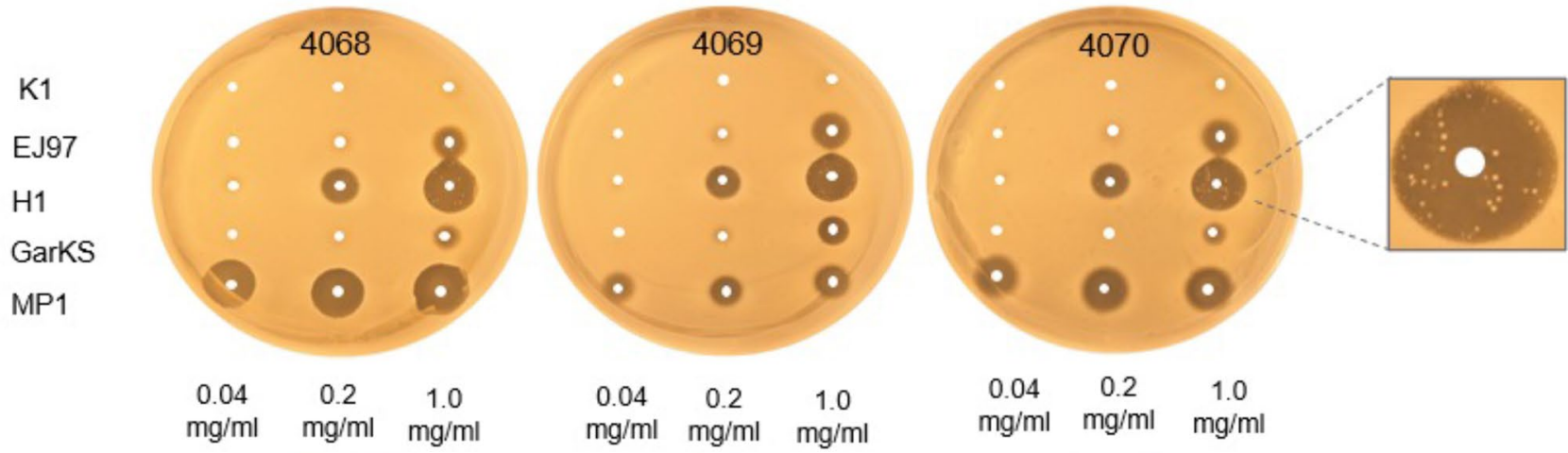

K1

EJ97

$\mathrm{H} 1$

GarkS

MP1
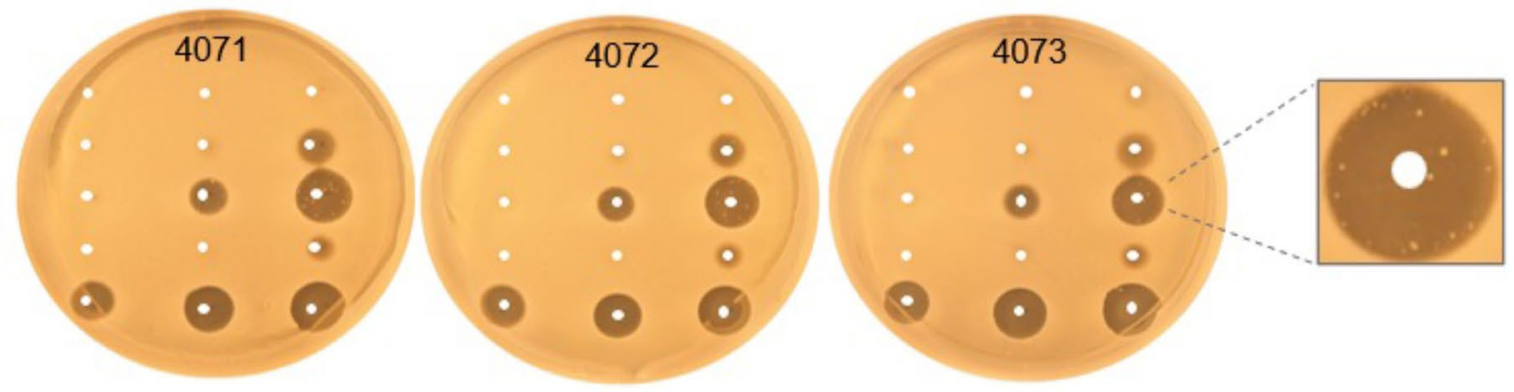

Figure 2. Comparison of the antimicrobial activities of the bacteriocins against $S$. haemolyticus. The antimicrobial activity of the indicated bacteriocins was assessed by "spot-on-lawn" assay against six $S$. haemolyticus strains, 4068-4073. The bacteriocins were applied at three different concentrations $(0.04,0.2$, and $1.0 \mathrm{mg} / \mathrm{ml}$ ), and $5 \mu \mathrm{l}$ of each was spotted on the lawns of the $S$. haemolyticus strains. All strains developed resistance to $\mathrm{H} 1$ after $24 \mathrm{~h}$ incubation, as illustrated for strains 4070 and 4073.

The tricomponent combination is effective against S. haemolyticus biofilms. The ability to form biofilms is a widespread virulence factor among CoNS; it is significantly associated with the colonization of prosthetic implants, increased antimicrobial resistance and therapeutic failure ${ }^{47}$. Among S. haemolyticus the genetic elements conferring adhesive properties and ultimately the ability to form biofilms are widely distributed ${ }^{48,49}$. In order to assess whether our clinical S. haemolyticus strains were indeed able to form biofilms in vitro, we performed a crystal violet assay on biofilm-associated cells ${ }^{50}$. Twelve $S$. haemolyticus isolates were included in the study, six of which were isolated from leprosy-associated skin ulcers in India (4068-4073), four were isolated from bacteremia patients and two were commensial isolates. We also included the methicillin-resistant S. aureus strain USA300 and a leprosy-associated S. arlettae strain as controls for a strong and a poor biofilm-former, respectively (Fig. S2) ${ }^{41,51}$. Using the crystal violet assay, the strong biofilm-former S. aureus USA300 produced an average OD value of over 3 (cut-off value for biofilm formers =1), while the poor biofilm-former S. arlettae gave an average OD value of 0.5 . All $S$. haemolyticus strains formed biofilms comparable to that of $S$. aureus USA300, except 7067_4_60 which produced an average OD value of 2 (Fig. S2). These results indicate that most pathogenic $S$. haemolyticus strains are strong biofilm-formers.

Given the strong antimicrobial effect of the tricomponent combination identified above, we wanted to examine its efficacy against biofilm-associated S. haemolyticus cells. We used a modified version of the biofilm-oriented antimicrobial test (BOAT) $)^{52,53}$ which allows the quantification of the metabolic activity (via the metabolic indicator triphenyl-tetrazolium chloride) within residual live cells within the biofilms after antimicrobial treatment. To do this, the $S$. haemolyticus biofilms were first allowed to form for $24 \mathrm{~h}$, then the biofilms were treated with the antimicrobials for 5, 24 or $48 \mathrm{~h}$, before the BOAT assay was performed (Fig. 4A; Fig. S3). We exposed biofilmassociated cells to a serial dilution of the tricomponent combination, starting with the highest concentrations (D0) being $625 \mu \mathrm{g} / \mathrm{ml}$ for $\mathrm{H} 1$ and garvicin $\mathrm{KS}$ and $62.5 \mu \mathrm{g} / \mathrm{ml}$ for micrococcin P1. These high values were 100 times higher the $\mathrm{MIC}_{50}$ values for planktonic cells, accounting for the higher resilience to antimicrobial treatment of biofilm-associated cells $s^{15,41,54}$. After $5 \mathrm{~h}$ the metabolic activity of all tested strains was very low or undetectable at all dilutions, except for 4069, which showed a residual metabolic activity at the highest dilution factors (D6 and D7) (Fig S3A). After a prolonged incubation for 24 and $48 \mathrm{~h}$, most strains showed resilience but only at the lowest concentrations D5 and D7. For strains 4071-4073, 7068_4_63 and SH14, little or no metabolic activity was seen at all dilutions (Fig. 4A; Fig. S3B).

Bacterial cells can remain dormant (with very low or no metabolic activity) within the biofilms ${ }^{55,56}$. If this was the case in our biofilm settings, these cells would be overlooked by the BOAT assay. To examine this issue, biofilm-associated $S$. haemolyticus cells were treated with the tricomponent combination at concentration D0 (e.g. $625 \mu \mathrm{g} / \mathrm{ml}$ for $\mathrm{H} 1$ and garvicin $\mathrm{KS}$ and $62.5 \mu \mathrm{g} / \mathrm{ml}$ for micrococcin P1) for $24 \mathrm{~h}$. This was followed by CFU counting to identify potential survinving cells in the treated biofilms. As shown in Fig. 4B, this treatment led 

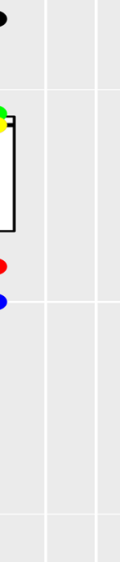
A

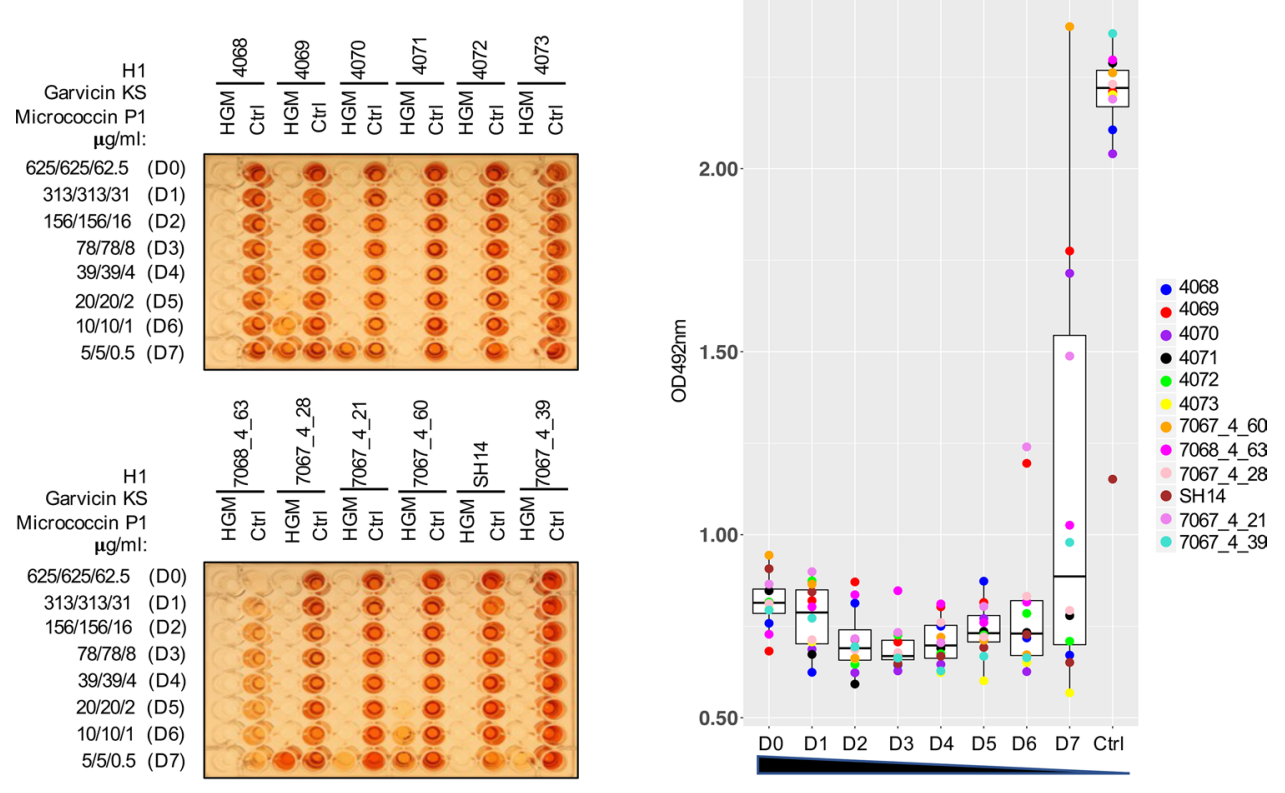

B

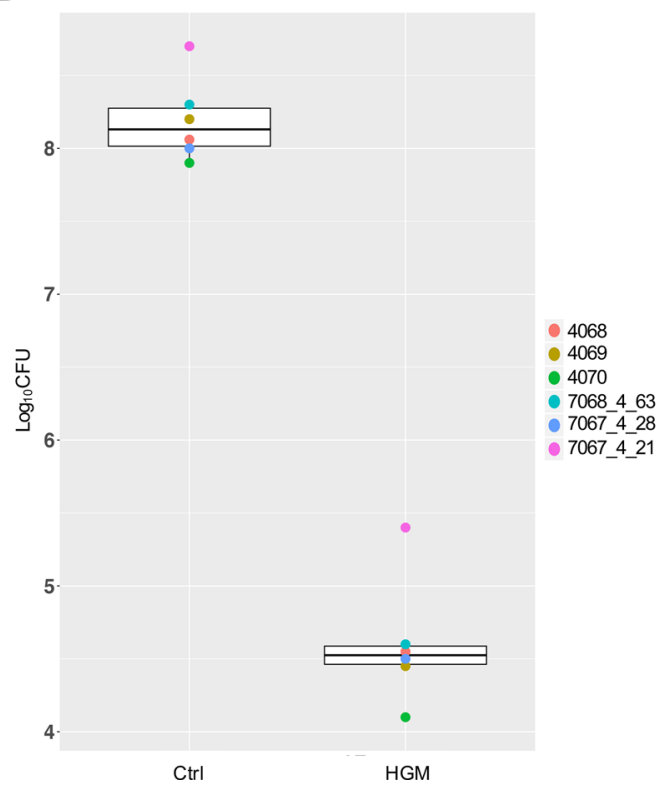

C
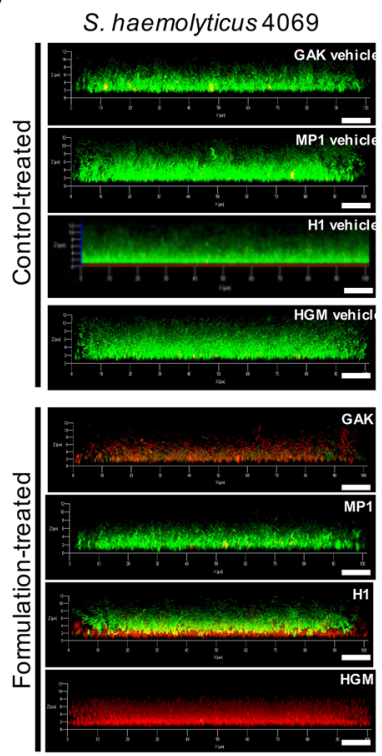

Figure 4. The tricomponent antimicrobial combination effectively inhibits the metabolic activity and viability of $S$.

haemolyticus biofilm-associated cells in vitro. (A) The left panels show representative images of BOAT assays performed upon $24 \mathrm{~h}$ treatment with the tricomponent combination (HGM: H1, GarKS, MP1) for the indicated strains. The concentration $(\mu \mathrm{g} /$ $\mathrm{ml}$ ) of the individual antimicrobials in the dilutions (dilution factors: D0 to D7) is indicated on the far left of the images. As controls, the assay was performed using the vehicles at their final concentrations (Ctrl). The development of red color indicates the retention of metabolic activity, and its quantification was performed by spectrophotometry at $\mathrm{OD}_{492}$. Metabolic activity values were plotted as a function of the dilution factor for the antimicrobial combination (right panel). Shown is the median distribution (thick line within boxes) and the degree of variability (amplitude of the box or inter quartile region (IQR)) of the metabolic activities for the indicated strains measured at increasing dilution factors (D0-D7). The boxplot components (whiskers and outliers) are displayed as specified in Fig. 3. Note that the treatment maintained the metabolic activitiy under detectable levels up to D6 for most strains. (B) The logarithmic colony formation unit ( $\left.\log _{10} \mathrm{CFU}\right)$ was calculated after the BOAT assays were performed for the indicated strains. BOAT assays were performed as in (A), and the boxplot shows the median distribution of the $\log _{10} \mathrm{CFU}$ values. The antimicrobial concentrations in the tricomponent combination were $625 \mu \mathrm{g} /$ $\mathrm{ml}$ for $\mathrm{H} 1$ and garvicin $\mathrm{KS}$ and $62.5 \mu \mathrm{g} / \mathrm{ml}$ for micrococcin P1. The control was performed by using the antimicrobials vehicles at their final concentration. (C) The S. haemolyticus strain 4069 was allowed to form biofilms on glass-bottomed chambers for $24 \mathrm{~h}$, prior to treatment with the indicated antimicrobials (lower set of panels) or the respective control-vehicles (upper set of panels) as detailed in (B). The biofilms were subsequently stained using the LIVE/DEAD biofilm staining kit and confocal microscope images were taken using a $63 \times$ oil immersion objective. Scale bars correspond to $10 \mu \mathrm{m}$. 
to a dramatic and statistically significant $(p<0.0001)$ reduction of the biofilm-associated cell viability, with a drop in $\log _{10} \mathrm{CFU}$ values ranging between 3.3 and 3.8 compared with the non-treated control for all six $S$. haemolyticus strains. These results were further confirmed by LIVE/DEAD biofilm staining followed by confocal microscopy analysis (Fig. 4C) which indeed showed only dead (red) cells within the biofilms when treated with the tricomponent combination. On the other hand, mixtures of live (green) and dead cells were observed when treated with the single antimcrobials. It is interesting to note that the treatment with $\mathrm{H} 1$ led to the killing of the bacterial cells in the deepest layers of the biofilm while preserving the cell viability in upper layers. This effect could not be observed for GarKS and MP1, possibly reflecting a mode of action and/or pattern of penetration within the biofilm specific for $\mathrm{H} 1$.

\section{Discussion}

In this study we described the generation of a hybrid bacteriocin (H1) obtained by the fusion of the N-and C-terminal parts of the enterocins $\mathrm{K} 1$ and EJ97, respectively. The resulting H1 shows much better activity against the important human pathogen S. haemolyticus compared with EJ97 and especially K1 (Table 1). Both parental enterocins are class-II leaderless antimicrobial peptides. They share high sequence homology with each other and both use the membrane-bound RseP as a receptor on target cells ${ }^{23}$. We have previously shown that within the LsbB-group which contains LsbB, EJ97 and K1, the C-terminal part of these bacteriocins dictates their target specificity while the $\mathrm{N}$-terminal part contains an amphiphilic alpha-helix which likely has the pore-forming function $^{23,57-60}$. Since H1 was composed of the C-terminal half of EJ97 and the N-terminal half of K1, it is reasonable to think that the hybrid bacteriocin would have an inhibition spectrum similar to EJ97. This notion was generally in line with the result presented in Table S1 which showed an overlapping inhibition spectrum between $\mathrm{H} 1$ and EJ97. Nevertheless, there were some few important differences: H1 displayed an activity against certain strains of B. cereus, C. pisciola, L. garvieae and S. arlettae that overlapped with K1. On the other hand, compared to both parental enterocins, H1 showed a higher activity against members of the genera Staphylococcus (S. aureus, S. epidermidis and S. haemolyticus) and Streptococcus (S. termophilus and S. uberis) (Table S1). This indicates that the K1's N-terminal half in H1, to some extent, also modulates the specificity of H1. Importantly, our analysis on 27 clinical S. haemolyticus strains indicated that the antimicrobial activity of K1 and EJ97 was highly straindependent, whereas H1 retained a high level of antimicrobial activity against all S. haemolyticus strains (Table 1).

It is worth mentioning that another hybrid peptide (H2) with an inverse order to $\mathrm{H} 1$ was also made, i.e., with an $\mathrm{N}$-terminal half from EJ97 and a C-terminal half from K1. However, unlike H1, the inverted peptide showed in general very low activity (data not shown), and therefore no further analysis was carried on this version. At present, we do not know why $\mathrm{H} 2$ had low antimicrobial activity, but this is beyond the scope of the present study.

Despite the increased activity against $S$. haemolyticus, the antimicrobial potential of $\mathrm{H} 1$ was unfortunately hampered by the rapid development of resistance. Previous studies highlighted that multicomponent antimicrobial combinations offer a superior efficacy in terms of antimicrobial activity and prevention of resistance development ${ }^{20,41,61,62}$. In this study, we assessed the efficacy of $\mathrm{H} 1$ in combination with garvicin KS and micrococcin P1. The former is a multi-peptide bacteriocin composed of three non-modified peptides and belongs to the leaderless family of bacteriocins (class IId) ${ }^{46}$. Its mode of killing has not been elucidated in detail. However, it is supposed to disrupt the cell membrane integrity leading to the leakage of intracellular fluids, followed by cell lysis and death (unpublished data). On the other hand, micrococcin P1 belongs to a class of microbial ribosomally-synthesized and post-translationally modified peptides (RiPPs) known as thiopeptides ${ }^{63}$; a group of protein synthesis inhibitors ${ }^{42-45}$. The combination of $\mathrm{H} 1$ with garvicin KS and micrococcin P1 elicited a significant reduction of the antimicrobial concentrations required to effectively inhibit the growth of both planktonic and biofilm-associated S. haemolyticus cells.

Consistent with our recent study on $S$. aureus biofilms ${ }^{41}$, a discrepancy between the inhibition of biofilmassociated metabolic activity and cell viability could be observed. Indeed, treatments that led to a complete abolishment of metabolic activity did not translate directly into a corresponding annihilation of the cell viability quantified by CFU counting. A likely explanation for such an effect is biofilm-associated cell dormancy. Bacterial dormancy is a well-documented phenomenon, which significantly contributes to the long-term persistence of bacterial cells ${ }^{55,56}$. The dormant phenotype is characterized by low levels of metabolic activity, which confers the reduced susceptibility to antimicrobials as most antibiotics only attack active metabolic pathways such DNA, RNA, protein, cell wall synthesis ${ }^{56,64}$. Therefore, it is conceivable that if persister cells do exist within the biofilms in our model, their metabolic activity might not be tracked in the BOAT assays; however, metabolic reactivation will occur once cells are transferred to an appropriate growth-promoting environment ${ }^{65,66}$.

Bacteriocin-based antimicrobial combinations have been widely explored against a variety of pathogenic bacteria, including biofilm-forming strains ${ }^{67,68}$. However, these studies primarily focused on investigating the interaction between bacteriocins and different classes of antibiotics or other bioactive molecules ${ }^{68-72}$. Recently, also garvicin KS and micrococcin P1 have been tested in combination with penicillin G against MRSA, showing a potent antimicrobial activity ${ }^{20,41}$. To our knowledge, the antimicrobial combination described in the present work is the first bacteriocin-based and antibiotic-free example. In our view, this has a significant advantage as it complies with the health authorities' general recommendations: namely to reduce or, where possible, avoid the use of antibiotics to treat bacterial infections. Similar recommendations were set by the European Commission (2015/C 299/04) also in veterinary medicine, particularly in the food production chain. In treating certain medical conditions, such as mastitis in dairy cows, antibiotic therapy will result in drug accumulation into the milk, leading to short-term withdrawal of milk from antibiotic-treated cows and as a consequence, significant economic loss for farmers. Thus, our bacteriocin-based and antibiotic-free approach can be a valuable solution in this context. 
A

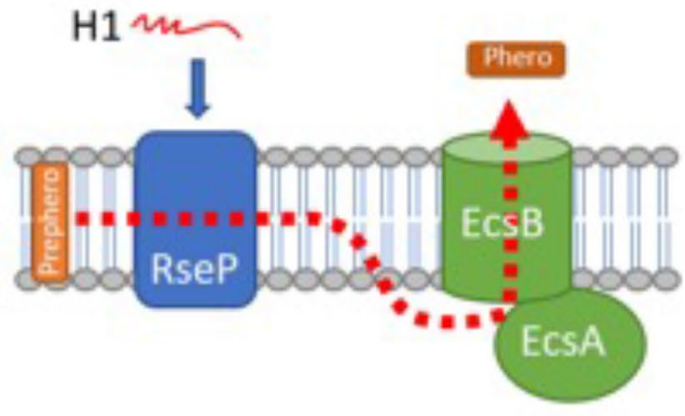

B

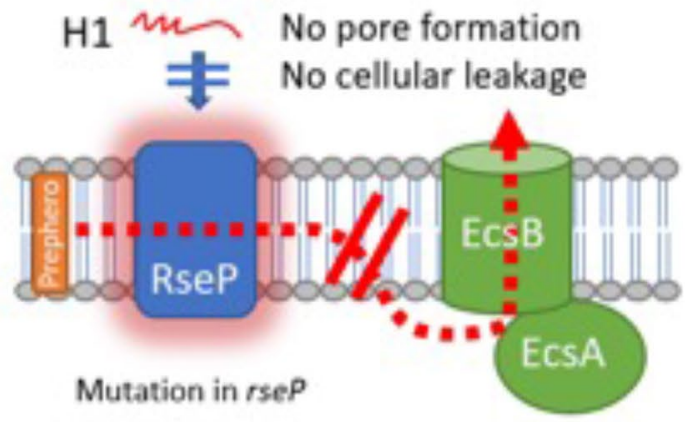

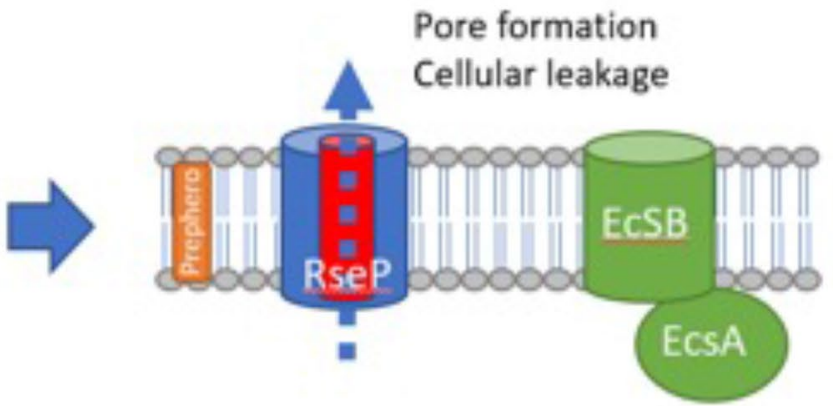

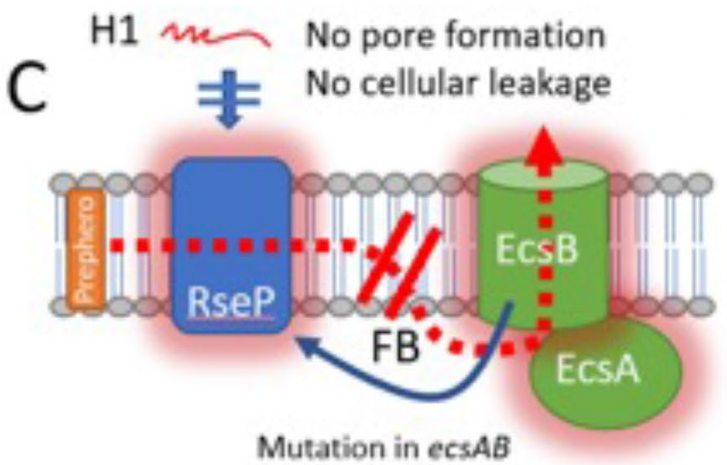

Figure 5. Proposed model for the EcsAB mediated H1-resistance in S.haemolyticus. (A) RseP is a innermembrane protease working together the ABC-transporter EcsAB to cleave the hormone prepeptide (Prephero) and export the mature hormone peptide (Phero) to the external milieu. RseP is acting also as the receptor for the bacteriocin $\mathrm{H} 1$ which forms pores and causes lethal cellular leakage across the membrane. (B) When $r s e P$ is mutated resulting in a non-functional receptor (RseP with glow), cells become resistant to H1. (C) When the ecs system is mutated, the malfunctional $\mathrm{ABC}$ transporter can no longer export the hormone peptide. This jammed situation of hormone prepeptide/peptide within the membrane results in a feedback (FB) loop somehow causing RseP inactivity. An inactive RseP (RseP with glow) loses its function as a bacteriocin receptor, and cells therefore become resistant to $\mathrm{H} 1$.

Our complementation studies using L. plantarum confirmed that RseP was indeed the target for H1 on the $S$. haemolyticus cells and was essential for its antimicrobial activity. Therefore it was very surprising to reveal that most $S$. haemolyticus $\mathrm{H} 1$-resistant mutants did not possess a disruptive mutation within the rseP gene. By WGS, we found that 4 out of 5 mutants contained mutations in the ecs $A B$ gene pair, which encodes components of the ATP-binding cassette $(\mathrm{ABC})$ transporter Ecs. The fact that mutations accumulated within the ABC transporter abolished the sensitivity to $\mathrm{H} 1 \mathrm{might}$ indicate a molecular link between Ecs and RseP. Interestingly, similar observations have also been found in other studies. In Bacillus subtilis the perturbation of the ecs $A B$ gene locus leads to the disruption of RasP function (RasP is a RseP homolog). In addition, inactivation of rasP led to an overlapping phenotype with $B$. subtilis strains carrying mutations in ecs $A^{39}$. In Enterococcus faecalis, EcsAB and Eep (the enterococcal homolog of RseP) are functionally connected in a quorum sensing pathway involved in conjugation $^{73}$. Eep is responsible for the processing of several pheromone precursors, including cCF10, cAD1 and $\mathrm{CAD}^{30,74}$, and the secretion of the mature sex pheromones is then mediated by EcsAB ${ }^{73}$, resulting in the conjugative transfer of mobile genetic elements; including antibiotic resistance determinants ${ }^{30,75}$. Similarly, the inactivation of an Eep-like metalloprotease in Streptococcus gordonii abolishes the secretion of the cAM373 pheromone $^{76}$. Based on these similarities, it is tempting to speculate that a similar mechanism is involved in the H1-resistant $S$. haemolyticus ecs mutants. In such a model as depicted in Fig. 5A, EcsAB is working downstream of RseP, to export an unknown product provided by RseP. Mutations in rseP will destroy its receptor function thereby allow cells becoming resistant to $\mathrm{H} 1$ (Fig. 5B). Mutations in ecs $A B$ will entail the accumulation of RseP-processed peptides in the cell membrane that may affect, in a feedback maner, the functionality of RseP, ultimately rendering RseP no longer suitable as the bacteriocin receptor (Fig. 5C). This model can also probably be applied to enterococci, since E. faecalis mutants which are resistant to EJ97 contain mutations either within $e c s A B$ or $r s e P$; however, a much higher frequency was observed in the latter ${ }^{77}$. Therefore, it was unexpected to find high frequency of mutations in ecs relative to $r s e P$ in $S$. haemolyticus. The molecular nature behind the different mutation rates in $r s e P$ and ecs $A B$ between these two pathogens is unknown, yet it might reflect the different roles of RseP in these two pathogens. Undoubtfully, the role of RseP and its connection with the Ecs system deserves further investigation in future studies. 
The high degree of genome plasticity of $S$. haemolyticus ${ }^{3}$ allows this bacterium to readily acquire resistance mehcanisms toward many different antibiotics. Here we demonstrated that using multiple bacteriocins with different modes of action can overcome the resistance problem in S. haemolyticus. The tricomponent combination with the bacteriocins H1, MP1 and GarKS proves effective both against planktonic and biofilm-associated cells, the latter being much troublesome in therapeutic treatment due to the protective biofilm layers. Our data indicate that the antimicrobials in the mixture were able to peneterate the protective biofilm layer and kill the bacterial cells hiding underneath. Antimicrobial peptides are ubiquitous in nature, and they are very diverse in terms of amino acid sequence, structure, modification, and mode of action. By genetic means, or by de novo synthesis, new hybrid antimicrobial peptides can be easily made to improve potency and/or alter target specificity, as demonstrated in the present study with $\mathrm{H} 1$. This approach can be a precious path to create novel antimicrobials and combat bacterial infections and antibiotic resistance.

\section{Materials and methods}

Bacterial strains and cultivation conditions. Bacterial strains used in this study are listed in Tables S1, S3 and S4. The following strains were cultivated in Brain heart infusion (BHI) broth (Oxoid): all indicator strains $\left(30{ }^{\circ} \mathrm{C}\right.$, with shaking), all clinical S. haemolyticus isolates (Table S2) and Escherichia coli (DH5a, TG1) $\left(37^{\circ} \mathrm{C}\right.$, with shaking). Lactobacillus plantarum (WCFS1) was cultivated in MRS broth (Oxoid) at $37^{\circ} \mathrm{C}$ without shaking. Agar plates were prepared by supplementing the appropriate broth with $1.5 \%$ (w/v) agar (VWR chemicals). When appropriate, erythromycin was added to a final concentration of $200 \mu \mathrm{g} / \mathrm{ml}$ for E.coli and $10 \mu \mathrm{g} / \mathrm{ml}$ for $L$. plantarum.

Bacteriocins and antimicrobial assays. Bacteriocins used in this study are listed in Table S5. K1 ${ }^{23}$, EJ97 $7^{31}$, $\mathrm{H} 1$ and garvicin KS peptides (Gak-A, $-\mathrm{B}$ and $-\mathrm{C})^{46}$ were synthesized by Pepmic Co., Ltd, China, with $>95 \%$ purity. These bacteriocins were all solubilized in $0.1 \%$ (vol/vol) trifluoracetic acid (TFA; Sigma-Aldrich). Micrococcin $\mathrm{P}^{78}$ was purchased from Cayman Chemical, Michigan, USA with ${ }^{3} 95 \%$ purity and solubilized in a $50 \%$ (v/v) mixture of isopropanol (Merck) with $0.1 \%(\mathrm{v} / \mathrm{v})$ TFA (Sigma-Aldrich) at a stock concentration of $1 \mathrm{mg} / \mathrm{ml}$.

A semi-quantitative spot-on-lawn inhibitory assay was performed on 51 bacterial indicator strains (Table S1) to determine the bacteriocins inhibition spectra. Overnight cultures were diluted 1:100 in BHI soft agar and distributed on BHI agar plates. Once solidified, bacteriocins with various concentrations were applied on designated spots. The plates were incubated at appropriate temperature $\mathrm{O} / \mathrm{N}$ and inhibition zones were measured the following day. To determine minimal inhibitory concentration $\left(\mathrm{MIC}_{50}\right)$ of $\mathrm{H} 1$ against clinical S. haemolyticus isolates (Table S2), as well as strains heterologously expressing RseP (Table S4), the microtiterplate antimicrobial assay was performed as previously described ${ }^{41,79}$. $\mathrm{MIC}_{50}$ was defined as the minimal bacteriocin concentration needs to inhibit the growth of a bacterial strain by at least $50 \%$.

Synergistic interactions between antimicrobials were determined using the fractional inhibition concentration (FIC) as previously described ${ }^{80}$. The FIC values were determined using a mirotiterplate checkerboard assay. Briefly, antimirobial A was applied in wells A1-H1 then diluted two-fold in wells 2-12. In a second microtiter plate, antimicrobial B was applied in wells A1-A12, then diluted two folds in wells B-H. Fifty $\mu$ l of the serial diluted antimirobial A was transferred to the wells of a third microtiter plate, except for wells H1-H12. Similarly, $50 \mu \mathrm{l}$ of the serial diluted antimicrobial B was transferred to the same microtiter plate, except for wells A1-A12. Wells H1-12 and wells A1-12 contained only one of the antimicrobials and was used to estimate the MIC value of the pure substance. After combining the antimicrobials, $100 \mu$ of a 1:25 diluted $\mathrm{O} / \mathrm{N}$ of $\mathrm{S}$. haemolyticus was transferred to each well of the third microplate, while $50 \mu$ of medium was added to wells H1-12 and A1-12. The plates where incubated at $37^{\circ} \mathrm{C}$ for 5,24 or $48 \mathrm{~h}$ before the MIC values were scored. FIC values were calculated as follows: FIC = FICa + FICb + FICc, where the FICa means MIC of A in combination/MIC of A alone, FICb means MIC of B in combination/MIC of B, and FICc means MIC of C in combination/MIC of C alone. Effects were considered as synergistic if FIC was $\leq 0.5$ for two components mixture ${ }^{81}$ and $\leq 0.75$ for three components mixture e $^{82}$.

Isolation of H1-resistant mutants. During the spot-on-lawn inhibitory assay on plates, H1-resistant $S$. haemolyticus isolates were observed within the inhibition zones. Resistant colonies within the inhibition zones with various $\mathrm{H} 1$-concentrations $(1 \mathrm{mg} / \mathrm{ml}$ or $10 \mathrm{mg} / \mathrm{ml})$ were re-streaked to obtain pure colonies. Glycerol stocks ( $15 \%$ glycerol v/v) of the pure cultures were made and stored at $-80{ }^{\circ} \mathrm{C}$ until use.

DNA sequencing. For $r s e P$ sequencing, $r s e P$ was PCR amplified using pure colonies or gDNA isolated from H1-resistant $S$. haemolyticus strains as a template. gDNA was isolated from the resistant mutants using NucleoSpin Genomic DNA kit from Microorganisms (Macherey-Nagel). rseP was amplified using Q5 Hot Start High-Fidelity DNA polymerase (New England Biolabs). PCR amplicons were purified using NucleoSpin Gel and PCR clean-up kit (Macherery-Nagel), sequenced at Eurofins GATC, Germany, and analysed using CLC Main Workbench (Qiagen) (https://digitalinsights.qiagen.com). Primers used for sequencing and PCR amplification are listed in Table S6. For whole genome sequencing, genomic DNA was sequenced using Illumina Next Generation Sequencing. Contigs were assembled using Unipro UGENE ${ }^{83}$, while SnapGene software (GSL Biotech), Blast (NCBI) and UniProt was applied in further downstream analysis.

Heterologous expression of rseP. $\quad$ rseP (Uniprot: Q4L5W4) derived from S. haemolyticus 7067_4_21 was heterologously expressed in the naturally H1-resistant $L$. plantarum WCFS $1^{36}$ using the vector pSIP expression system ${ }^{84,85}$. First, pLp1261_InvS, a pSIP401 derivative ${ }^{84,86}$, was linearized using FastDigest Restrictiction Enzymes NdeI and Acc65I (ThermoFisher Scientific) to isolate the vector part. Second, $r s e P$ was amplified by PCR using specially designed In-Fusion Primes (Table S6), giving amplicons with complementary ends to the 
linearized vector. The In-Fusion HD cloning Kit (Takara Bio) was used to fuse rseP into the linearized vector, yielding pSIP401_SHRseP. The plasmid was subsequently transformed to E.coli TOP10 (ThermoFischer Scientific). Plasmid DNA from E. coli was isolated using NucleoSpin Plasmid Kit (Macherey-Nagel). The DNA sequence of all PCR amplified fragments was verified by sequencing at Eurofins GATC, Germany, and before being electroporated into L. plantarum WCSF1 following the procedure described by Aukrust and Blom ${ }^{87}$.

Biofilm formation assay. A microtiter dish biofilm formation assay was performed to determine the biofilm forming ability of $S$. haemolyticus strains. Briefly, the optical density measured at $600 \mathrm{~nm}\left(\mathrm{OD}_{600}\right)$ of O/N cultures was adjusted to 0.5 by diluting the cultures in 3\% Tryptic Soy Broth (TSB; Sigma-Aldrich). This was followed by further diluting $10 \mathrm{ml}$ of the relevant bacterial supentions in $90 \mathrm{ml}$ of $3 \%$ TSB supplemented with 1\% glucose in the appropriate wells of a 96 -well plate (Sarstedt) and incubated at $37^{\circ} \mathrm{C}$ for $24 \mathrm{~h}$. Following incubation, the $\mathrm{O} / \mathrm{N}$ culture medium was removed and the presence of biofilms within the inoculated wells was first assessed visually. For quantification, the biofilms were washed twice with $100 \mu \mathrm{l}$ of $0.9 \% \mathrm{NaCl}$, incubated at $55^{\circ} \mathrm{C}$ for $1 \mathrm{~h}$ to fix the biofilm forming cells to the plastic surface and then stained with a $0.5 \%$ crystal violet solution for $10 \mathrm{~min}$ at room temperature. Excess crystal violet solution was removed, and the biofilms were further washed with $100 \mu \mathrm{l}$ of $0.9 \% \mathrm{NaCl}$ three times. The residual biofilm-bound crystal violet was then extracted by incubating the wells with $100 \mathrm{ml}$ of absolute ethanol (Sigma-Aldrich) for $10 \mathrm{~min}$. The extraction procedure was repeated twice, and the amount of crystal violet extracted was quantified at $\mathrm{OD}_{600}$. The quantification of the crystal violet released from the biofilm is a surrogate measure of the biofilm formation ability of a strain.

Biofilm-oriented antimicrobial test (BOAT). To assess the antimicrobial effects of bacteriocins on biofilm-associated $S$. haemolyticus cells, the metabolic activity of biofilm-associated cells was determined by using the biofilm-oriented antimicrobial test (BOAT), as previously described ${ }^{41,52}$. H1, garvicin KS and micrococin P1 were assessed individually or in combinations, using a serial two-fold dilution scheme of their concentration. Unless otherwise stated, the starting dilutions were $625 \mu \mathrm{g} / \mathrm{ml}$ for $\mathrm{H} 1$ and garvicin $\mathrm{KS}, 62.5 \mu \mathrm{g} / \mathrm{ml}$ for micrococcin P1. Biofilms were allowed to form for $24 \mathrm{~h}$ as described above and subsequently challenged with the bacteriocins, individually or in combinations, for 5,24 or $48 \mathrm{~h}$ at $37^{\circ} \mathrm{C}$. As negative control, the assay was performed using the vehicles to their working concentration (i.e., without bacteriocins).

Determination of persister cells within biofilms after BOAT. The procedure for the BOAT assay was repeated as above, with one exception. Instead of monitoring the residual metabolic activity of biofilm-associated cells after the bacteriocin challenge, bacteriocin-treated cells were resuspended in TSB and further serially diluted. The serial diluted bacterial cells were plated on BHI agar plates and incubated at $37^{\circ} \mathrm{C}$ for $24 \mathrm{~h}$. Colony forming units $(\mathrm{CFU} / \mathrm{ml})$ were used to quantify the remaining surviving cells after antimicrobial challenge.

Confocal microscopy of biofilms. Biofilms were allowed to grow for $24 \mathrm{~h}$ as described above except that they were formed in the wells of chambered cover-glass plates (Thermo Fisher Scientific) before being challenged for $24 \mathrm{~h}$ with the single bacteriocins or combinations diluted in TSB. The biofilms were subsequently analyzed using the LIVE/DEAD Biofilm Viability Kit (Molecular Probes, Thermo Fisher Scientific) according to the manufacturer's instruction. Z-stacks of the stained biofilms were then taken on a confocal laser scanning microscope (Zeiss), using a $488 \mathrm{~nm}$ argon laser line for exciting the SYTO-9 (green-live cells) dye and a $561 \mathrm{~nm}$ laser line for the propidium iodide (red-dead cells). The bacteriocin concentrations used were the same as described for the BOAT assay. The control vehicles for the single bacteriocins and their combination were used at the following concentrations: 0,0063\% (v/v) TFA for H1; garvicin KS, 0,003\% (v/v) TFA; 3,1\% (v/v) 2-propanol for micrococcin P1.

Received: 22 April 2021; Accepted: 15 June 2021

Published online: 06 July 2021

\section{References}

1. Becker, K., Heilmann, C. \& Peters, G. Coagulase-negative staphylococci. Clin. Microbiol. Rev. 27, 870-926. https://doi.org/10.1128/ CMR.00109-13 (2014).

2. Czekaj, T., Ciszewski, M. \& Szewczyk, E. M. Staphylococcus haemolyticus-An emerging threat in the twilight of the antibiotics age. Microbiology (Reading) 161, 2061-2068. https://doi.org/10.1099/mic.0.000178 (2015).

3. Takeuchi, F. et al. Whole-genome sequencing of staphylococcus haemolyticus uncovers the extreme plasticity of its genome and the evolution of human-colonizing staphylococcal species. J. Bacteriol. 187, 7292-7308. https://doi.org/10.1128/JB.187.21.7292-7308. 2005 (2005).

4. Silva, P. V. et al. The antimicrobial susceptibility, biofilm formation and genotypic profiles of Staphylococcus haemolyticus from bloodstream infections. Mem. Inst. Oswaldo Cruz 108, 812-813. https://doi.org/10.1590/0074-0276108062013022 (2013).

5. Klingenberg, C. et al. Persistent strains of coagulase-negative staphylococci in a neonatal intensive care unit: virulence factors and invasiveness. Clin. Microbiol. Infect. 13, 1100-1111 (2007).

6. Fredheim, E. G. et al. Biofilm formation by Staphylococcus haemolyticus. J. Clin. Microbiol. 47, 1172-1180. https://doi.org/10.1128/ JCM.01891-08 (2009).

7. Barros, E. M., Ceotto, H., Bastos, M. C., Dos Santos, K. R. \& Giambiagi-deMarval, M. Staphylococcus haemolyticus as an important hospital pathogen and carrier of methicillin resistance genes. J. Clin. Microbiol. 50(1), 166-8 (2012).

8. Cavanagh, J. P. et al. Whole-genome sequencing reveals clonal expansion of multiresistant Staphylococcus haemolyticus in European hospitals. J. Antimicrob. Chemother. 69, 2920-2927. https://doi.org/10.1093/jac/dku271 (2014). 
9. Froggatt, J. W., Johnston, J. L., Galetto, D. W. \& Archer, G. L. Antimicrobial resistance in nosocomial isolates of Staphylococcus haemolyticus. Antimicrob. Agents Chemother. 33, 460-466. https://doi.org/10.1128/aac.33.4.460 (1989).

10. Veach, L., Pfaller, M., Barrett, M., Koontz, F. \& Wenzel, R. Vancomycin resistance in Staphylococcus haemolyticus causing colonization and bloodstream infection. J. Clin. Microbiol. 28, 2064-2068 (1990).

11. Hanssen, A. M., Kjeldsen, G. \& Sollid, J. U. Local variants of Staphylococcal cassette chromosome mec in sporadic methicillinresistant Staphylococcus aureus and methicillin-resistant coagulase-negative Staphylococci: evidence of horizontal gene transfer?. Antimicrob. Agents Chemother. 48, 285-296. https://doi.org/10.1128/aac.48.1.285-296.2004 (2004).

12. Berglund, C. \& Soderquist, B. The origin of a methicillin-resistant Staphylococcus aureus isolate at a neonatal ward in Swedenpossible horizontal transfer of a staphylococcal cassette chromosome mec between methicillin-resistant Staphylococcus haemolyticus and Staphylococcus aureus. Clin. Microbiol. Infect. 14, 1048-1056. https://doi.org/10.1111/j.1469-0691.2008.02090.x (2008).

13. Fluit, A. C., Carpaij, N., Majoor, E. A., Bonten, M. J. \& Willems, R. J. Shared reservoir of $c c r B$ gene sequences between coagulasenegative staphylococci and methicillin-resistant Staphylococcus aureus. J. Antimicrob. Chemother. 68, 1707-1713. https://doi.org/ $10.1093 / \mathrm{jac} / \mathrm{dkt121}(2013)$.

14. Mack, D. et al. Biofilm formation in medical device-related infection. Int. J. Artif. Organs 29, 343-359 (2006).

15. Mah, T. F. \& O’Toole, G. A. Mechanisms of biofilm resistance to antimicrobial agents. Trends Microbiol. 9, 34-39. https://doi.org/ 10.1016/s0966-842x(00)01913-2 (2001).

16. Neely, A. N. \& Maley, M. P. Survival of enterococci and staphylococci on hospital fabrics and plastic. J. Clin. Microbiol. 38, 724-726. https://doi.org/10.1128/JCM.38.2.724-726.2000 (2000).

17. Nascimento, J. et al. Bacteriocins as alternative agents for control of multiresistant staphylococcal strains. Lett. Appl. Microbiol. 42, 215-221 (2006).

18. Cotter, P. D., Ross, R. P. \& Hill, C. Bacteriocins-a viable alternative to antibiotics?. Nat. Rev. Microbiol. 11, 95-105. https://doi. org/10.1038/nrmicro2937 (2013).

19. Goldstein, B. P., Wei, J., Greenberg, K. \& Novick, R. Activity of nisin against Streptococcus pneumoniae, in vitro, and in a mouse infection model. J. Antimicrob. Chemother. 42, 277-278 (1998).

20. Ovchinnikov, K. V., Kranjec, C., Thorstensen, T., Carlsen, H. \& Diep, D. B. Successful development of bacteriocins into therapeutic formulation for treatment of MRSA skin infection in a murine model. Antimicrob. Agents Chemother. https://doi.org/10.1128/ AAC.00829-20 (2020).

21. Bartoloni, A. et al. In-vitro activity of nisin against clinical isolates of Clostridium difficile. J. Chemother. 16, 119-121 (2004).

22. Hanchi, H. et al. Inhibition of MRSA and of Clostridium difficile by durancin 61A: Synergy with bacteriocins and antibiotics. Future Microbiol. 12, 205-212. https://doi.org/10.2217/fmb-2016-0113 (2017).

23. Ovchinnikov, K. V. et al. The leaderless bacteriocin enterocin K1 is highly potent against Enterococcus faecium: A study on structure, target spectrum and receptor. Front. Microbiol. 8, 774. https://doi.org/10.3389/fmicb.2017.00774 (2017).

24. Reinseth, I. S., Ovchinnikov, K. V., Tonnesen, H. H., Carlsen, H. \& Diep, D. B. The increasing issue of vancomycin-resistant enterococci and the bacteriocin solution. Probiot. Antimicrob. Proteins 12, 1203-1217. https://doi.org/10.1007/s12602-019-09618-6 (2020).

25. Frank, K. L. et al. Use of recombinase-based in vivo expression technology to characterize Enterococcus faecalis gene expression during infection identifies in vivo-expressed antisense RNAs and implicates the protease Eep in pathogenesis. Infect. Immun. 80, 539-549. https://doi.org/10.1128/IAI.05964-11 (2012).

26. Frank, K. L. et al. AhrC and Eep are biofilm infection-associated virulence factors in Enterococcus faecalis. Infect. Immun. 81, 1696-1708. https://doi.org/10.1128/IAI.01210-12 (2013).

27. Kanehara, K., Ito, K. \& Akiyama, Y. YaeL (EcfE) activates the sigma(E) pathway of stress response through a site-2 cleavage of anti-sigma(E), RseA. Genes Dev. 16, 2147-2155. https://doi.org/10.1101/gad.1002302 (2002).

28. Ellermeier, C. D. \& Losick, R. Evidence for a novel protease governing regulated intramembrane proteolysis and resistance to antimicrobial peptides in Bacillus subtilis. Genes Dev. 20, 1911-1922. https://doi.org/10.1101/gad.1440606 (2006).

29. Kroos, L. \& Akiyama, Y. Biochemical and structural insights into intramembrane metalloprotease mechanisms. Biochim. Biophys. Acta 2873-2885, 2013. https://doi.org/10.1016/j.bbamem.2013.03.032 (1828).

30. An, F. Y., Sulavik, M. C. \& Clewell, D. B. Identification and characterization of a determinant (eep) on the Enterococcus faecalis chromosome that is involved in production of the peptide sex pheromone cAD1. J. Bacteriol. 181, 5915-5921. https://doi.org/10. 1128/JB.181.19.5915-5921.1999 (1999).

31. Galvez, A. et al. Isolation and characterization of enterocin EJ97, a bacteriocin produced by Enterococcus faecalis EJ97. Arch. Microbiol. 171, 59-65. https://doi.org/10.1007/s002030050678 (1998).

32. Tiwari, S. K., Sutyak Noll, K., Cavera, V. L. \& Chikindas, M. L. Improved antimicrobial activities of synthetic-hybrid bacteriocins designed from enterocin E50-52 and pediocin PA-1. Appl. Environ. Microbiol. 81, 1661-1667. https://doi.org/10.1128/AEM. 03477-14 (2015).

33. Acuna, L., Picariello, G., Sesma, F., Morero, R. D. \& Bellomio, A. A new hybrid bacteriocin, Ent35-MccV, displays antimicrobial activity against pathogenic Gram-positive and Gram-negative bacteria. FEBS Open Bio 2, 12-19. https://doi.org/10.1016/j.fob. 2012.01.002 (2012).

34. Fimland, G. et al. New biologically active hybrid bacteriocins constructed by combining regions from various pediocin-like bacteriocins: The C-terminal region is important for determining specificity. Appl. Environ. Microbiol. 62, 3313-3318. https://doi.org/ 10.1128/AEM.62.9.3313-3318.1996 (1996).

35. Waterhouse, A. et al. SWISS-MODEL: Homology modelling of protein structures and complexes. Nucleic Acids Res. 46, W296W303 (2018).

36. Kleerebezem, M. et al. Complete genome sequence of Lactobacillus plantarum WCFS1. Proc. Natl. Acad. Sci. USA 100, 1990-1995. https://doi.org/10.1073/pnas.0337704100 (2003).

37. Kontinen, V. P. \& Sarvas, M. Mutants of Bacillus subtilis defective in protein export. J. Gen. Microbiol. 134, 2333-2344. https://doi. org/10.1099/00221287-134-8-2333 (1988).

38. Leskela, S., Kontinen, V. P. \& Sarvas, M. Molecular analysis of an operon in Bacillus subtilis encoding a novel ABC transporter with a role in exoprotein production, sporulation and competence. Microbiology (Reading) 142(Pt 1), 71-77. https://doi.org/10. 1099/13500872-142-1-71 (1996).

39. Heinrich, J., Lunden, T., Kontinen, V. P. \& Wiegert, T. The Bacillus subtilis ABC transporter EcsAB influences intramembrane proteolysis through RasP. Microbiology (Reading) 154, 1989-1997. https://doi.org/10.1099/mic.0.2008/018648-0 (2008).

40. Jonsson, I. M. et al. Inactivation of the Ecs ABC transporter of Staphylococcus aureus attenuates virulence by altering composition and function of bacterial wall. PLOS ONE 5, e14209. https://doi.org/10.1371/journal.pone.0014209 (2010).

41. Kranjec, C. et al. A bacteriocin-based antimicrobial formulation to effectively disrupt the cell viability of methicillin-resistant Staphylococcus aureus (MRSA) biofilms. NPJ Biofilms Microbiomes 6, 58. https://doi.org/10.1038/s41522-020-00166-4 (2020).

42. Otaka, T. \& Kaji, A. Micrococcin: Acceptor-site-specific inhibitor of protein synthesis. Eur. J. Biochem. 50, 101-106. https://doi. org/10.1111/j.1432-1033.1974.tb03876.x (1974).

43. Ciufolini, M. A. \& Lefranc, D. Micrococcin P1: Structure, biology and synthesis. Nat. Prod. Rep. 27, 330-342. https://doi.org/10. 1039/b919071f (2010).

44. Mikolajka, A. et al. Differential effects of thiopeptide and orthosomycin antibiotics on translational GTPases. Chem. Biol. 18, 589-600. https://doi.org/10.1016/j.chembiol.2011.03.010 (2011). 
45. Zheng, Q. et al. Thiopeptide antibiotics exhibit a dual mode of action against intracellular pathogens by affecting both host and microbe. Chem. Biol. 22, 1002-1007. https://doi.org/10.1016/j.chembiol.2015.06.019 (2015).

46. Ovchinnikov, K. V. et al. Novel group of leaderless multipeptide bacteriocins from gram-positive bacteria. Appl. Environ. Microbiol. 82, 5216-5224. https://doi.org/10.1128/AEM.01094-16 (2016).

47. Rogers, K. L., Fey, P. D. \& Rupp, M. E. Coagulase-negative staphylococcal infections. Infect. Dis. Clin. North Am. 23, 73-98. https:// doi.org/10.1016/j.idc.2008.10.001 (2009).

48. Soumya, K. R., Philip, S., Sugathan, S., Mathew, J. \& Radhakrishnan, E. K. Virulence factors associated with Coagulase Negative Staphylococci isolated from human infections. 3 Biotech 7, 140. https://doi.org/10.1007/s13205-017-0753-2 (2017).

49. Tremblay, Y. D. et al. Characterization of the ability of coagulase-negative staphylococci isolated from the milk of Canadian farms to form biofilms. J. Dairy Sci. 96, 234-246. https://doi.org/10.3168/jds.2012-5795 (2013).

50. Stepanovic, S. et al. Quantification of biofilm in microtiter plates: Overview of testing conditions and practical recommendations for assessment of biofilm production by staphylococci. APMIS 115, 891-899. https://doi.org/10.1111/j.1600-0463.2007.apm_630.x (2007).

51. Vanhommerig, E. et al. Comparison of biofilm formation between major clonal lineages of methicillin resistant Staphylococcus aureus. PLoS ONE 9, e104561. https://doi.org/10.1371/journal.pone.0104561 (2014).

52. Gronseth, T. et al. Lugol's solution eradicates Staphylococcus aureus biofilm in vitro. Int. J. Pediatr. Otorhinolaryngol. 103, 58-64. https://doi.org/10.1016/j.ijporl.2017.09.025 (2017).

53. Moussa, S. H. \& Farouk, A. Tetrazolium/formazan test as anefficient method to determine fungal chitosan antimicrobial activity. J. Mycol. https://doi.org/10.1155/2013/753692 (2013).

54. Ito, A., Taniuchi, A., May, T., Kawata, K. \& Okabe, S. Increased antibiotic resistance of Escherichia coli in mature biofilms. Appl. Environ. Microbiol. 75, 4093-4100. https://doi.org/10.1128/AEM.02949-08 (2009).

55. Pu, Y., Ke, Y. \& Bai, F. Active efflux in dormant bacterial cells-New insights into antibiotic persistence. Drug Resist. Updat. 30, 7-14. https://doi.org/10.1016/j.drup.2016.11.002 (2017).

56. Wood, T. K., Knabel, S. J. \& Kwan, B. W. Bacterial persister cell formation and dormancy. Appl. Environ. Microbiol. 79, 7116-7121. https://doi.org/10.1128/AEM.02636-13 (2013).

57. Johnsen, L., Fimland, G. \& Nissen-Meyer, J. The C-terminal domain of pediocin-like antimicrobial peptides (class IIa bacteriocins) is involved in specific recognition of the C-terminal part of cognate immunity proteins and in determining the antimicrobial spectrum. J. Biol. Chem. 280, 9243-9250. https://doi.org/10.1074/jbc.M412712200 (2005).

58. Fimland, G., Johnsen, L., Dalhus, B. \& Nissen-Meyer, J. Pediocin-like antimicrobial peptides (class IIa bacteriocins) and their immunity proteins: Biosynthesis, structure, and mode of action. J. Pept. Sci. 11, 688-696. https://doi.org/10.1002/psc.699 (2005).

59. Saavedra, L., Minahk, C., de Ruiz Holgado, A. P. \& Sesma, F. Enhancement of the enterocin CRL35 activity by a synthetic peptide derived from the NH2-terminal sequence. Antimicrob. Agents Chemother. 48, 2778-2781. https://doi.org/10.1128/AAC.48.7.27782781.2004 (2004).

60. Salvucci, E., Saavedra, L. \& Sesma, F. Short peptides derived from the NH2-terminus of subclass IIa bacteriocin enterocin CRL35 show antimicrobial activity. J. Antimicrob. Chemother. 59, 1102-1108. https://doi.org/10.1093/jac/dkm096 (2007).

61. Xu, X. et al. Synergistic combination of two antimicrobial agents closing each other's mutant selection windows to prevent antimicrobial resistance. Sci. Rep. 8, 7237. https://doi.org/10.1038/s41598-018-25714-z (2018).

62. Doern, C. D. When does 2 plus 2 equal 5? A review of antimicrobial synergy testing. J. Clin. Microbiol. 52, 4124-4128. https://doi. org/10.1128/JCM.01121-14 (2014).

63. Zhang, Y., Chen, M., Bruner, S. D. \& Ding, Y. Heterologous production of microbial ribosomally synthesized and post-translationally modified peptides. Front. Microbiol. 9, 1801. https://doi.org/10.3389/fmicb.2018.01801 (2018).

64. Dawson, C. C., Intapa, C. \& Jabra-Rizk, M. A. Persisters": Survival at the cellular level. PLoS Pathog 7, e1002121. https://doi.org/ 10.1371/journal.ppat.1002121 (2011).

65. Marimon, O. et al. An oxygen-sensitive toxin-antitoxin system. Nat. Commun. 7, 13634. https://doi.org/10.1038/ncomms13634 (2016).

66. Dworkin, J. \& Shah, I. M. Exit from dormancy in microbial organisms. Nat. Rev. Microbiol. 8, 890-896. https://doi.org/10.1038/ nrmicro2453 (2010).

67. Newstead, L. L., Varjonen, K., Nuttall, T. \& Paterson, G. K. Staphylococcal-produced bacteriocins and antimicrobial peptides: Their potential as alternative treatments for Staphylococcus aureus infections. Antibiotics (Basel) https://doi.org/10.3390/antibiotic s9020040 (2020).

68. Mathur, H. et al. Fighting biofilms with lantibiotics and other groups of bacteriocins. NPJ Biofilms Microbiomes 4, 9. https://doi. org/10.1038/s41522-018-0053-6 (2018).

69. Zgheib, H., Drider, D. \& Belguesmia, Y. Broadening and enhancing bacteriocins activities by association with bioactive substances. Int. J. Environ. Res. Public Health. https://doi.org/10.3390/ijerph17217835 (2020).

70. Fahim, H. A., Khairalla, A. S. \& El-Gendy, A. O. Nanotechnology: A valuable strategy to improve bacteriocin formulations. Front. Microbiol. 7, 1385. https://doi.org/10.3389/fmicb.2016.01385 (2016).

71. Mataraci, E. \& Dosler, S. In vitro activities of antibiotics and antimicrobial cationic peptides alone and in combination against methicillin-resistant Staphylococcus aureus biofilms. Antimicrob. Agents Chemother. 56, 6366-6371. https://doi.org/10.1128/AAC. 01180-12 (2012).

72. Dosler, S. \& Mataraci, E. In vitro pharmacokinetics of antimicrobial cationic peptides alone and in combination with antibiotics against methicillin resistant Staphylococcus aureus biofilms. Peptides 49, 53-58. https://doi.org/10.1016/j.peptides.2013.08.008 (2013).

73. Varahan, S., Harms, N., Gilmore, M. S., Tomich, J. M. \& Hancock, L. E. An ABC transporter is required for secretion of peptide sex pheromones in Enterococcus faecalis. mBio 5, e01726-e01714. https://doi.org/10.1128/mBio.01726-14 (2014).

74. Chandler, J. R. \& Dunny, G. M. Characterization of the sequence specificity determinants required for processing and control of sex pheromone by the intramembrane protease Eep and the plasmid-encoded protein PrgY. J. Bacteriol. 190, 1172-1183. https:// doi.org/10.1128/JB.01327-07 (2008).

75. Dunny, G., Funk, C. \& Adsit, J. Direct stimulation of the transfer of antibiotic resistance by sex pheromones in Streptococcus faecalis. Plasmid 6, 270-278. https://doi.org/10.1016/0147-619x(81)90035-4 (1981).

76. Vickerman, M. M. et al. A genetic determinant in Streptococcus gordonii Challis encodes a peptide with activity similar to that of enterococcal sex pheromone cAM373, which facilitates intergeneric DNA transfer. J. Bacteriol. 192, 2535-2545. https://doi.org/ 10.1128/JB.01689-09 (2010).

77. Reinseth, I., Tonnesen, H. H., Carlsen, H. \& Diep, D. B. Exploring the therapeutic potenital of the leaderless enterocins K1 and EJ97 in the treatment of vancomycin-resistant enterococcal infection. Front. Microbiol. 12, 649339. https://doi.org/10.3389/fmicb. 2021.649339 (2021).

78. Su, T. L. Micrococcin, an antibacterial substance formed by a strain of Micrococcus. Br. J. Exp. Pathol. 29, 473-481 (1948).

79. Chi, H. \& Holo, H. Synergistic antimicrobial activity between the broad spectrum bacteriocin garvicin KS and nisin, farnesol and polymyxin B against gram-positive and gram-negative bacteria. Curr. Microbiol. 75, 272-277. https://doi.org/10.1007/s00284-017$1375-y(2018)$

80. Orhan, G., Bayram, A., Zer, Y. \& Balci, I. Synergy tests by E test and checkerboard methods of antimicrobial combinations against Brucella melitensis. J. Clin. Microbiol. 43, 140-143. https://doi.org/10.1128/JCM.43.1.140-143.2005 (2005). 
81. Neu, H. C. \& Fu, K. P. Synergy of azlocillin and mezlocillin combined with aminoglycoside antibiotics and cephalosporins. Antimicrob. Agents Chemother. 13, 813-819. https://doi.org/10.1128/aac.13.5.813 (1978).

82. Bhusal, Y., Shiohira, C. M. \& Yamane, N. Determination of in vitro synergy when three antimicrobial agents are combined against Mycobacterium tuberculosis. Int. J. Antimicrob. Agents 26, 292-297. https://doi.org/10.1016/j.ijantimicag.2005.05.005 (2005).

83. Okonechnikov, K., Golosova, O. \& Fursov, M.; UGENE Team. Unipro UGENE: A unified bioinformatics toolkit. Bioinformatics 28, 1166-1167. https://doi.org/10.1093/bioinformatics/bts091 (2012).

84. Sorvig, E. et al. Construction of vectors for inducible gene expression in Lactobacillus sakei and L. plantarum. FEMS Microbiol. Lett. 229, 119-126. https://doi.org/10.1016/S0378-1097(03)00798-5 (2003).

85. Sorvig, E., Mathiesen, G., Naterstad, K., Eijsink, V. G. H. \& Axelsson, L. High-level, inducible gene expression in Lactobacillus sakei and Lactobacillus plantarum using versatile expression vectors. Microbiology (Reading) 151, 2439-2449. https://doi.org/10. 1099/mic.0.28084-0 (2005)

86. Fredriksen, L. et al. Surface display of N-terminally anchored invasin by Lactobacillus plantarum activates NF-kappaB in monocytes. Appl. Environ. Microbiol. 78, 5864-5871. https://doi.org/10.1128/AEM.01227-12 (2012).

87. Holck, A., Axelsson, L., Birkeland, S. E., Aukrust, T. \& Blom, H. Purification and amino acid sequence of sakacin A, a bacteriocin from Lactobacillus sakei Lb706. J. Gen. Microbiol. 138, 2715-2720. https://doi.org/10.1099/00221287-138-12-2715 (1992).

\section{Acknowledgements}

This study was financed by the Research Council of Norway (Project Nos. 275190 and 273646) and by Grant support from Indian Council for Medical Research, GoI (Grant No.: AMR/IN/113/2013/2017-ECD/II). The funders had no role in study design, data collection and interpretation, or the decision to submit the work for publication.

\section{Author contributions}

C.K. and S.K. designed the experiments, analysed the data and wrote the paper. K.T.B and M.B. performed the experiments and contributed to the data analysis. J.P.C. and A.S. provided the S. haemolyticus clinical strains used in the study. G.M. and D.B.D. obtained funding, designed the experiments and revised the paper.

\section{Competing interests}

The authors declare no competing interests.

\section{Additional information}

Supplementary Information The online version contains supplementary material available at https://doi.org/ 10.1038/s41598-021-93158-z.

Correspondence and requests for materials should be addressed to D.B.D.

Reprints and permissions information is available at www.nature.com/reprints.

Publisher's note Springer Nature remains neutral with regard to jurisdictional claims in published maps and institutional affiliations.

(c) (i) Open Access This article is licensed under a Creative Commons Attribution 4.0 International License, which permits use, sharing, adaptation, distribution and reproduction in any medium or format, as long as you give appropriate credit to the original author(s) and the source, provide a link to the Creative Commons licence, and indicate if changes were made. The images or other third party material in this article are included in the article's Creative Commons licence, unless indicated otherwise in a credit line to the material. If material is not included in the article's Creative Commons licence and your intended use is not permitted by statutory regulation or exceeds the permitted use, you will need to obtain permission directly from the copyright holder. To view a copy of this licence, visit http://creativecommons.org/licenses/by/4.0/.

(C) The Author(s) 2021 